Voix et Images

\title{
Télévision. Du bon usage du cancer au téléthéâtre
}

\section{Jean-Pierre Duquette}

Volume 6, numéro 3, printemps 1981

Philippe Haeck

URI : https://id.erudit.org/iderudit/200297ar

DOI : https://doi.org/10.7202/200297ar

Aller au sommaire du numéro

Éditeur(s)

Les Presses de l'Université du Québec

ISSN

0318-9201 (imprimé)

1705-933X (numérique)

Découvrir la revue

Citer cet article

Duquette, J.-P. (1981). Télévision. Du bon usage du cancer au téléthéâtre. Voix et Images, 6(3), 511-512. https://doi.org/10.7202/200297ar d'utilisation que vous pouvez consulter en ligne.

https://apropos.erudit.org/fr/usagers/politique-dutilisation/ 


\title{
Télévision \\ Du bon usage du cancer \\ au téléthéâtre
}

\author{
par Jean-Pierre Duquette
}

On a peu parlé de la troublante production réalisée par Robert Desrosiers, à l'écran de Radio-Québec fin janvier: De jour en jour. La pièce d'André Caron se déroule toute dans ce qu'on appelle, euphémisme doucement sinistre, une "unité de soins palliatifs", comme il en existe dans quelques grands hôpitaux aujourd'hui. II s'agit, on l'aura compris, de quartiers réservés aux cancéreux avancés, en "stade terminal», et où l'on s'efforce d'aider les malades à «mourir dignement». Dignement pour qui, du reste: d'abord pour les survivants, sans aucun doute. A défaut de savoir précisément ce qu'est le cancer, on invente à coups de millions des "palliatifs", seulement cela, comme l'indiquait récemment dans le Devoir le Pr Jean-Paul Escande : « .. . actuellement, la seule façon qu'ont nos sociétés d'aborder le cancer c'est de dire : «Le cancer, on va l'engloutir sous les dollars, l'engloutir sous les machines...» En vérité. il devrait être écrit à la porte de ces services: «Vous qui entrez ici, perdez tout espoir. Car il ne s'agit même plus du grand dilemme: dire ou ne pas dire, savoir ou ne pas savoir... Ici, l'on sait à coup sûr, d'une manière indubitable.

"Le soleil ni la mort ne se peuvent regarder en face», avait écrit La Roche Foucault, repris par Montherlant qui l'a pourtant très bien envisagée, la mort, au point de se la donner en toute lucidité, ultime choix d'homme libre. Il s'agit ici de la mort certaine, qui prend (parfois) tout son temps et savoure sa victoire, tandis que chacun se débrouille comme il peut dans la confusion de son attente. André Caron a réuni dans De jour en jour un éventail de patients représentatifs, si l'on ose dire: le travailleur dans la cinquantaine, qui noie sa douleur (et son angoisse?) dans le gros "gin " sans faire d'histoires; le vieux garçon fortuné qui. enrage à l'idée de laisser son argent et sa Jaguar à une sœur et un neveu âpres à l'héritage; Madame Berthe, pétulante quinquagénaire, tout de même nostalgique à l'idée de ses charmes de jadis, mais qui semble en prendre philosophiquement son parti; le directeur d'école d'administration, début de la quarantaine, cadre dynamique qui refuse presque jusqu'au bout de croire à l'inéluctable; et le jeune «bum» d'Abitibi, qui dit carrément non à la fatalité en choisissant de se suicider (il avale d'un coup tous les médicaments «palliatifs» qu'on lui a apportés depuis des jours). 
Signe des temps dans la société québécoise d'après la Révolution tranquille : le «secours de la foi » est à tout prendre absent, malgré la présence d'un aumônier qui distribue la communion à tour de bras. Le personnel dévoué est fidèle au poste, avec tout de même de légers mouvements d'impatience: le médecin réaliste et compréhensif est toujours là; on organise un succédané de Fête de Noël, mais le cœur n'y est pas tout à fait, faut-il même y insister... Car ELLE est là, présence lancinante et horrible, et qui aura le dernier mot, dignité ou pas. Ce n'est jamais qu'une question de semaines, de jours.

Peut-être pire encore que le fait de savoir que la fin est proche: les demi-mensonges pieux, rassurants, comme cela arrive souvent. II y a quelques semaines dans un grand hebdomadaire français, on lisait sur trois pages l'expérience et le témoignage atroce d'une fille de vingt ans à qui l'on a fait croire qu'elle avait $50 \%$ de chances de s'en tirer, alors que la biopsie était on ne peut plus claire. Se trouvant seule un matin dans un bureau attenant a la salle de radiation, elle a ouvert son propre dossier et elle a su. Après le cobalt, la chimiothérapie. Et c'est alors qu'elle a refusé de continuer le traitement. Non pas résignée à mourir: plutôt révoltée qu'on lui ait laissé espérer tout ce temps qu'elle pourrait s'en tirer. Elle rejette l'idée d'être prolongée, de "vivre à moitié», de "faire confiance plus longtemps à la médecine, de prendre un pari sur l'avenir.» $A$ toutes ces questions elle répond lucidement: "La tumeur, c'est moi qui l'ai. On ne prend pas de pari sur une tumeur. (...) Je préfère rester moins longtemps en vie, mais profiter de tous les instants... Et ne pas souffrir pour rien.»

Le Pr Léon Schwarzenberg, autre autorité mondiale, est catégorique: «Le malade doit avoir le droit de choisir. " Même si, dans le cas de cette jeune femme, il trouve regrettable qu'on lui ait d'abord raconté des histoires, et qu'elle en soit venue à cette décision terrible. Ce n'est pas elle, en tout cas, qu'on ira visiter dans ces mouroirs climatisés que sont les «unités de soins palliatifs», ce qu'on a trouvé de mieux à inventer avec l'embaumement des cadavres coiffés et fardés, portant parfois leurs lunettes : le mort est «présentable», rassurant, presque vivant ( On dirait qu'il dort...»; ou mieux encore: «... qu'elle va parler!»). Ici, c'est d'embaumement moral qu'il s'agit, avant l'autre. Dans les deux cas, ça fait vraiment une belle jambe.

La production de Radio-Québec n'a pas remporté le Prix Louis-Philippe Kammans, de la Communauté des télévisions de langue française. Sans avoir vu les autres dramatiques en lice, De jour en jour était excellent, avec des dialogues serrés, efficaces, une trame condensée, sans fioritures inutiles. Le thème hautement chargé d'émotivité a été traité par André Caron d'une manière froide, comme détachée, clinique, ce qui vaut infiniment mieux que tous les apitoiements et les attendrissements fleur bleue. Le texte était superbement vécu par des comédiens au métier indiscutable : Olivette Thibault, Paul Hébert, Michel Dumont, Marc Messier, Aubert Pallascio et quelques autres. Un grand téléthéâtre, où passait toute l'âpre vérité de la mort en face, malgré tous les «soins palliatifs» du monde. 